\title{
O colágeno em fáscia transversal de pacientes com hérnia inguinal direta submetidos à videolaparoscopia ${ }^{1}$
}

\author{
Igor Wolwacz Júnior ${ }^{2}$ \\ Manoel Roberto Maciel Trindade ${ }^{3}$ \\ Carlos Thadeu Cerski ${ }^{4}$
}

\begin{abstract}
Wolwacz Jr I, Trindade MRM, Cerski CT. O colágeno em fáscia transversal de pacientes com hérnia inguinal direta submetidos à videolaparoscopia. Acta Cir Bras [serial online] 2003 MaioJun;18(3). Disponível em URL: http://www.scielo.br/acb.

RESUMO - Objetivo: Analisar quanto à espessura, elementos constitutivos e quantificação do colágeno total amostras de fáscias transversais de pacientes entre 20 e 60 anos de idade, com hérnia inguinal direta, coletadas no momento da correção videolaparoscópica, comparando-as com amostras do mesmo tecido, retiradas de cadáveres. Métodos: Biopsias de 23 pacientes e de 22 cadáveres foram analisadas e comparadas. Utilizaram-se as técnicas de coloração de HematoxilinaEosina e Picrosirius. As imagens captadas foram analisadas por técnica videomorfométrica assistida por computador. Resultados: Constatou-se uma espessura de fáscia transversal nos controles, em média, de 4.5 milímetros. A espessura da fáscia transversal dos pacientes com hérnia foi, em média, $58 \%$ menor ( $\mathrm{p}<0.001$ ). Não se evidenciou algum processo de degeneração das fibras de colágeno atribuível à senilidade. $O$ principal elemento constitutivo da fáscia, nos dois grupos, foi o tecido conjuntivo denso, representando cerca de $75 \%$ nos controles e sendo um terço menor nos pacientes $(\mathrm{p}<0.001)$. A área média percentual de colágeno no campo amostral dos pacientes encontrada foi metade da área dos controles $(\mathrm{p}<0.001)$, resultando em uma menor quantidade de colágeno na parede posterior herniada. Conclusão: Os pacientes com hérnia inguinal direta apresentam menor quantidade de colágeno tanto absoluta quanto relativamente aos demais elementos constitutivos da fáscia transversal.
\end{abstract}

DESCRITORES - Colágeno. Hérnia inguinal. Fáscia transversal. Videolaparoscopia.

\section{Introdução}

A importância da hérnia inguinal não reside unicamente no fato de tratar-se da mais freqüente hérnia do ser humano. Estima-se que um homem em 5 e uma mulher em 17 poderão desenvolvê-la ao longo de suas vidas. Além disso, o enorme impacto sócio-econômico pode ser avaliado por dados estatísticos norteamericanos de 1991, quando foram realizadas cerca de 750.000 intervenções cirúrgicas ${ }^{1}$. No entanto, é ainda hoje na frustração terapêutica de uma parcela considerável de pacientes e cirurgiões que estabelecemos toda a complexidade desta doença. Segundo vários autores, os índices de recidiva pós-tratamento variam de 05 a $30 \%{ }^{2,3}$.

Nas últimas três décadas foram realizados estudos mais específicos sobre a importância da fragilidade da

1. Trabalho realizado no Departamento de Pós-graduação em Cirurgia da Faculdade de Medicina da Universidade Federal do Rio Grande do Sul.

2. Mestre em Cirurgia pela Universidade Federal do Rio Grande do Sul.

3. Prof. Dr. Adjunto de Cirurgia da Faculdade de Medicina da Universidade Federal do Rio Grande do Sul.

4. Prof. Dr. Adjunto de Patologia da Faculdade de Medicina da Universidade Federal do Rio Grande do Sul. 
parede posterior no desenvolvimento da hérnia inguinal 4,5,6,7,8,9. Todos estes trabalhos reconhecem a função crítica do colágeno de atribuir resistência e integridade estrutural às aponeuroses e fáscias. Nesta condição, a presença em quantidade adequada assim como as propriedades do colágeno são essenciais para a funcionalidade da fáscia transversal.

As observações de $\operatorname{Read}^{4}$ quanto à presença de bainha do músculo reto abdominal mais frágil, com menor peso por área que os controles e ainda mais evidentes nos pacientes com hérnia bilateral, suscitaram dúvidas quanto à presença de quantidades adequadas de colágeno na região inguinal.

Estudos posteriores ${ }^{5,6}$ sugeriram um decréscimo de hidroxiprolina e, portanto, colágeno, na bainha do músculo reto abdominal de pacientes com hérnia inguinal indireta e direta. Uma taxa de proliferação fibroblástica em culturas menor que a normal também foi relatada ${ }^{10}$.

Mais recentemente surgiram evidências, por meio de trabalhos ${ }^{11}$ com cultura de fibroblastos, de alteração quantitativa de colágeno tipo I e colágeno tipo III. A maior produção de colágeno tipo III em relação ao colágeno tipo I pelos fibroblastos dos pacientes com hérnia poderia justificar o adelgaçamento da parede posterior e sua fraqueza.

No entanto, um estudo ${ }^{12}$ com pacientes com hérnia inguinal direta e indireta foi realizado por meio de biópsias da fáscia transversal. Foram utilizados os métodos bioquímicos de eletroforese e eletroimunoensaio (ELISA) para criação de uma taxa de colágeno tipo I / colágeno tipo III, não tendo sido possível demonstrar diferenças entre os grupos.
A correção da hérnia inguinal deve ser feita a partir do conhecimento etiopatogênico. Através dele será possível definir as melhores técnicas cirúrgicas, obtendo-se assim os menores índices de recidiva. Por tratar-se de aponeurose, a parede posterior tem como estrutura fundamental as fibras de colágeno. Os autores se propõem a realizar um estudo quantitativo destas fibras na fáscia transversal que poderá contribuir para o conhecimento de alguns aspectos da etiopatogenia da hérnia inguinal.

\section{Métodos}

Realizou-se estudo de caso-controle em que foram investigados 23 pacientes que passaram pelos critérios de inclusão e exclusão atendidos no ambulatório de Cirurgia Geral, no Hospital de Clínicas de Porto Alegre, no período de abril de 1997 a agosto de 1999. Os critérios de inclusão adotados foram os seguintes: pacientes com diagnóstico de hérnia inguinal direta primária unilateral, de aparecimento inferior a 5 anos, do sexo masculino, com termo de consentimento assinado e maiores de 20 anos e menores de 60 anos. Foram excluídos os pacientes: do sexo feminino; em uso de medicamentos; portadores de Diabetes Mellitus, Hipertensão, DBPOC; portadores da Síndrome de Marfan, Osteogenisis imperfecta e Síndrome de EhlersDanlos; tabagistas; cirurgias infra-umbilicais; menores de 20 anos ou maiores de 60 anos.

O grupo controle foi formado por 22 cadáveres no Departamento Médico Legal de Porto Alegre (DML) masculinos com até 10 horas de falecimento, com termo de consentimento assinado por familiar e entre 20 e 60 anos. Foram excluídos os cadáveres do sexo feminino e menores de 20 ou maiores de 60 anos (Tabela 1).

TABELA 1 - Caracterização dos grupos por faixa etária.

\begin{tabular}{ccc}
\hline Idade $($ anos $)$ & Pacientes $(\mathbf{n}=\mathbf{2 3})$ & Controles $(\mathbf{n}=\mathbf{2 2})$ \\
\hline $\mathbf{2 0}-\mathbf{2 9}$ & 7 & 5 \\
$\mathbf{3 0}-\mathbf{3 9}$ & 6 & 7 \\
$\mathbf{4 0}-\mathbf{4 9}$ & 5 & 5 \\
$\mathbf{5 0}-\mathbf{5 9}$ & 5 & 5 \\
\hline Idade média dos grupos* & $38,65-11,20$ & $38,77-10,57$ \\
\hline
\end{tabular}

* Média de anos \pm desvio padrão, NS

\section{Procedimentos}

Os pacientes foram atendidos durante a rotina no ambulatório, sendo informados quanto ao protocolo de pesquisa. Ao concordarem em participar, foram colhidos os dados referentes aos critérios de inclusão e exclusão.

Após anestesia geral, foi iniciado o procedimento videolaparoscópico com a visualização dos orifícios herniários e abertura do peritôneo na parede posterior 
da região inguinal. Identificada a hérnia direta, esta foi reduzida e então retirou-se a amostra de fáscia transversal no Triângulo de Hesselbach .

A porção de fáscia transversal que fora retirada permanecia em solução de formalina, para fixação e posterior estudo histoquímico. Seguiu-se a colocação da tela e o fechamento do peritônio, conforme preconiza a técnica de reparo TAPP (transabdominal pré-peritoneal), com o término do procedimento.

Para a realização do grupo-controle foram realizadas visitas ao DML, onde foram identificados cadáveres masculinos, com até dez horas pós-mortem e sem evidência de hérnia inguinal. Durante a necropsia foram coletadas as amostras de fáscia transversal.

Ao ser completado o número de amostras dos dois grupos, criou-se uma tabela de códigos para cegamento da avaliação. As peças foram mensuradas em sua espessura, utilizando-se paquímetro. A seguir, fracionou-se a amostra em 3 porções equivalentes, as quais foram desidratadas em concentrações crescentes de etanol, clarificadas em xilol e incluídas em parafina.

Os blocos assim obtidos foram escolhidos aleatoriamente para utilização em uma das 2 técnicas de coloração ou como reserva. O estudo histopatológico foi realizado no Serviço de Patologia do HCPA.

As técnicas de coloração empregadas neste trabalho foram as seguintes: método da hematoxilinaeosina e método de Picrosirius ${ }^{13}$.

A avaliação das lâminas coradas com Picrosirius foi realizada mediante luz polarizada. Utilizou-se um sistema de imagens formado por um microscópio Olympus (Tóquio,Japão) com uma videocâmera Sony (Tóquio,Japão) acoplada. O sinal de video foi digitalizado em 24 bits em um computador pessoal Pentium
133 Megahertz (MHz), com uma resolução de 640 (horizontal) por 480 (vertical) pixels e 16 milhões de cores. A partir do aplicativo ImagePro Plus (Media Cybernetics,Silverspring,U.S.A.), realizou-se a contagem das áreas preenchidas por colágeno e nas áreas sem este elemento (vazio), em quatro campos amostrais aleatórios de dez campos. Para a análise dos resultados aplicaram-se os seguintes testes:

1- Teste $t$ para amostras independentes - para comparar as médias de idade, espessura da fáscia, área percentual de colágeno na fáscia e a área percentual de colágeno no campo amostral nos grupos e subgrupos etários;

2- Análise da variância para a área percentual de colágeno na fáscia e área percentual de colágeno no campo amostral ajustada para idade.

Em todos os testes fixou-se em 0,01 ou $1 \%$ ( $\Rightarrow$ ฯ 0,01) o nível de rejeição da hipótese de nulidade, assinalando-se com um asterisco os valores significantes. O protocolo deste estudo foi aprovado pelo Grupo de Pesquisa e Pós-Graduação, pela Comissão de Ética do Hospital de Clínicas de Porto Alegre e liberado pelo departamento científico do DML. Todos os pacientes forneceram consentimento informado para participarem da pesquisa.

\section{Resultados}

As fáscias dos grupos de pacientes e controles foram mensuradas quanto a sua espessura e os valores encontrados são apresentados na tabela 2. Os pacientes apresentaram amostras com espessura menor que os controles $(\mathrm{p}<0.001)$ e quando a análise comparou os grupos levando-se em consideração a idade menor ou maior que 39 anos, a diferença se manteve $(\mathrm{p}<0.001)$.

TABELA 2 - Espessura da fáscia transversal em milímetros.

\begin{tabular}{lcc}
\hline & PACIENTES & CONTROLES \\
\hline$<$ de 39 anos & $2.08(1.18-2.98)^{*}$ & $4.16(3.23-5.09)^{*}$ \\
$>$ de 39 anos & $1.72(0.72-2.72)^{*}$ & $4.9(3.62-6.18)^{*}$ \\
Total & $1.9(0.96-2.84)^{*}$ & $4.5(3.36-5.64)^{*}$ \\
\hline
\end{tabular}

média - desvio padrão

$* \mathrm{p}<0.001$, Teste $\mathrm{t}$ de Student

O tecido predominante das fáscias foi, em ambos os grupos, o conjuntivo denso, formado fundamentalmente pelas fibras de colágeno, e em menor percentagem, o tecido adiposo. A área percentual média de colágeno nas fáscias dos pacientes foi um terço menor que a área média de colágeno nas fáscias do grupo controle. Os valores podem ser vistos na tabela 3 . 
TABELA 3 - Médias percentuais de colágeno na fáscia.

\begin{tabular}{lcc}
\hline & PACIENTES & CONTROLES \\
\hline ÁREA \% DE COLÁGENO NO TECIDO & $49.97(6.09)^{*}$ & $75.86(6.06)^{*}$ \\
\hline
\end{tabular}

média \pm desvio padrão

$* \mathrm{p}<0.001$, Teste $\mathrm{t}$ de Student

Não foi encontrada uma variação da área ao longo da faixa etária de 20 à 60 anos como pode ser percentual média de colágeno, em ambos os grupos, visto na tabela 4.

TABELA 4 - Área percentual média de colágeno na fáscia por subgrupo etário.

\begin{tabular}{lll}
\hline & $<$ de 39 anos & $\geq$ de 40 anos \\
\hline PACIENTES & $50.00(6.96)$ & $49.94(7.19)$ \\
CONTROLES & $76.48(3.94)$ & $75.12(8.11)$ \\
\hline
\end{tabular}

média \pm desvio padrão

\# NS

No campo amostral, a área percentual média de colágeno, nos pacientes, foi a metade da encontrada no grupo controle. Os valores são apresentados na tabela
5. Esta variável representa de forma indireta a quantidade de colágeno absoluto presente na parede posterior da região inguinal.

TABELA 5 - Médias percentuais de colágeno no campo amostral.

\begin{tabular}{lll}
\hline & PACIENTES & CONTROLES \\
\hline ÁREA \% DE COLÁGENO NO CAMPO AMOSTRAL & $28.54(5.16)$ & $64.38(7.35) *$ \\
\hline média \pm desvio padrão & & \\
$* \mathrm{p}<0.001$, Teste $\mathrm{t}$ de Student & &
\end{tabular}

Não foi encontrada uma variação da área percentual média de colágeno no campo amostral, em ambos os grupos, ao longo da faixa etária de 20 à 60 anos como pode ser visto na tabela 6. Portanto, a quantidade de colágeno não sofreu alterações significativas com o passar do tempo.

TABELA 6 - Área percentual média de colágeno no campo amostral por subgrupo etário.

\begin{tabular}{lll}
\hline & $<$ de 39 anos & $\geq$ de 40 anos \\
\hline PACIENTES & $29.35(5.59)$ & $27.48(4.60)$ \\
CONTROLES & $64.80(4.74)$ & $63.88(9.90)$ \\
\hline
\end{tabular}

média \pm desvio padrão

\# NS

Para todos os valores de área encontrados foi realizada análise de variância (ANOVA) evidenciando- se a ausência de efeito da idade sobre os resultados dos grupos. 


\section{Discussão}

A hérnia é uma das afecções cirúrgicas mais freqüentes e que demandam do cirurgião um refinado conhecimento anatômico e de técnicas. No entanto, nossos conhecimentos sobre os mecanismos bioquímicos e metabólicos que incidem sobre a etiopatogenia da hérnia são escassos. O presente trabalho está baseado na possibilidade da existência de uma associação entre uma alteração nas proporções e quantidade do principal constituinte da fáscia transversal, o colágeno, e a fragilização da parede posterior do canal inguinal, como condição precípua para a herniogênese.

Para a realização deste estudo, utilizamo-nos de biópsias da fáscia transversal de pacientes portadores de hérnia inguinal direta, por meio de videolaparoscopia, comparando-as com amostras obtidas de fáscias normais de cadáveres. Não encontramos na literatura algum trabalho que tenha realizado semelhante desenho metodológico. $\mathrm{O}$ fato de realizarmos as biópsias no momento da correção videolaparoscópica permitiu-nos precisarmos a identificação e a ressecção da fáscia na hérnia direta. Por outro lado, as biópsias dos cadáveres foram retiradas no momento da autópsia, fato este que contribuiu para a facilidade de sua execução pela via intra-abdominal.

Os critérios de exclusão dos pacientes com hérnia inguinal direta incluíram o uso crônico de medicações, como os corticosteróides e o tabagismo. Estes mesmos critérios de exclusão não puderam, infelizmente, ser utilizados nos controles, devido à falta de dados precisos. Sobre este aspecto, nosso grupo de controles poderia apresentar fáscias comprometidas com os efeitos deletérios referidos anteriormente.

A espessura da aponeurose de reto abdominal mais fina e com menor peso por área em pacientes com hérnia direta foi constatada por READ ${ }^{4}$. Este e outros autores $^{5,7,8,10}$, sempre aludiram à hipótese de que o processo de interferência sobre a quantidade de colágeno nestas aponeuroses se refletiria igualmente na fáscia transversal.

Nossos resultados demonstraram uma fáscia transversal com espessura em torno de duas vezes menor nos pacientes que nos controles $(\mathrm{p}<0.001)$. Esta é a primeira vez que uma informação quantitativa sobre esta variável é apresentada. Da mesma forma, as médias das espessuras das fáscias apresentaram pouca variação nos subgrupos etários, tanto nos casos como nos controles (NS). Este resultado faz crer que não ocorre um processo de degeneração das fibras de colágeno, atribuível à senilidade, num período de 20 a 60 anos de idade, na fáscia transversal de pessoas com ou sem hérnia direta.
Poucos estudos ${ }^{12,14}$ basearam-se em amostras de fáscia transversal de pacientes com hérnia para acessar a distribuição dos seus elementos constituintes e quantificar o colágeno.

Para conhecermos a contribuição do colágeno na formação da fáscia patológica e na fáscia normal, valemo-nos de cortes histológicos transversais, escolhidos aleatoriamente, corados com Picrosirius e observados com luz polarizada. Este método tem sido largamente empregado em pesquisas sobre colágeno com resultados confiáveis ${ }^{15}$. Foi utilizado o processo de captação de imagens para video e mensuração videomorfométrica por computador, método este que apresenta uma boa correlação com a quantificação de hidroxiprolina por medida bioquímica como já descrito em trabalhos cardiológicos ${ }^{15}$.

O principal constituinte da fáscia era o tecido conjuntivo denso, formado caracteristicamente por colágeno. Em nossos grupos, o tecido conjuntivo denso foi o constituinte predominante em todas as amostras, seguido pelo tecido adiposo. A análise realizada evidenciou uma área percentual média de colágeno, nos pacientes, cerca de $33 \%$ menor que os controles $(p<0.001)$. Por outro lado, o achado de uma área média percentual de colágeno na fáscia dos controles de cerca de $75 \%$ está em acordo com WAGH e READ ${ }^{5}$, que relataram ser a aponeurose de músculo reto abdominal constituída de pelo menos $80 \%$ por colágeno. Estes resultados apontam para uma diminuição da importância do colágeno na formação da fáscia transversal dos pacientes, em contrapartida a uma maior participação dos demais tecidos constitutivos e, em particular, do tecido adiposo. Não sabemos se esta diferença se deve a fibroblastos defeituosos, à deficiente síntese proteica ou a um aumento da colagenólise. Fato é que tal diferença poderia justificar o aparecimento da hérnia ou atuar como forte promotor deste processo.

Peacock ${ }^{14}$ mensurou o total de colágeno bioquimicamente em fáscias de 5 pacientes com hérnias recidivadas e, por autopareamento, não encontrou quantidades alteradas. Outro trabalho ${ }^{12}$ de 1997 não reportou diferenças significativas na quantidade de colágeno no seu grupo de pacientes.Nós, por outro lado, ao mensurarmos a área média percentual de colágeno no campo amostral, pudemos comparar, indiretamente, a quantidade de colágeno nas amostras. Como resultado obtido, foi constatado que a área média percentual de colágeno no campo amostral dos pacientes era a metade da área dos controles $(p<0.001)$. Este resultado reflete, em parte, a menor espessura das fáscias dos pacientes e, como medida indireta, permite-nos inferir que existe menos colágeno na parede posterior dos pacientes com hérnia direta do que na parede dos indivíduos sem esta 
doença. A dissonância com os resultados de Peacock ${ }^{14}$ poderia ser explicada por suas amostras terem sido coletadas de pacientes herniogênicos, já em sua quarta recidiva e que foram comparadas às fáscias do outro lado, possivelmente doentes. Já as quantidades de colágeno nas fáscias coletadas no estudo espanhol ${ }^{12}$ são relativas aos grupos comparados entre hérnia direta e indireta, ou seja, controles que poderiam, também, ser considerados doentes.

Os resultados expostos neste trabalho reforçam sugestões de estudos anteriores de que a fáscia transversal de pacientes com hérnia direta apresenta alterações na quantidade de colágeno. Não é possível estabelecer uma relação de causa e efeito inequívoca a partir deste estudo. No entanto, nossos resultados trazem interessantes implicações terapêuticas, pois, em se tratando de uma fáscia doente, esta não deveria ser utilizada como tecido de sustentação para correção de um defeito herniário. Ainda assim, sugerimos a realização de novas pesquisas com quantificação imuno-histoquímica do colágeno em seus tipos I e III e análise das possíveis alterações sofridas pelo sistema elástico da fáscia transversal dos pacientes com hérnia direta e indireta. Estes estudos poderiam trazer importantes contribuições ao esclarecimento da hérnia, tão largamente tratada e tão pouco entendida.

\section{Conclusões}

Encontrou-se fáscia transversal do grupo controle com uma espessura média de 4,5 $\mathrm{mm}$ e que se apresenta $58 \%$ menor nos pacientes com hérnia direta. O tecido conjuntivo denso é o constituinte predominante nas fáscias com ou sem hérnia, seguido pelo tecido adiposo. No grupo controle a fáscia é constituída por cerca de $75 \%$ de colágeno. Já nos pacientes ela apresenta, em média, uma fração constitutiva percentual de colágeno cerca de $33 \%$ menor. Não se conseguiu evidenciar algum processo de degeneração das fibras de colágeno, atribuível à senilidade, num período de 20 a 60 anos de idade, na fáscia transversal de pessoas com ou sem hérnia direta. A área média percentual de colágeno no campo amostral dos pacientes é a metade da área dos controles.

\section{Referências}

1. Read RC. Basic features of abdominal wall herniation and its repair. In Shackelford's surgery of the alimentary tract. 4ed. George D. Zuidema, 1996.

2. Schumpelick V, Treutner KH, Arlt G. Inguinal hernia repair in adults. Lancet 1994;344:409-19.

3. Liem MSL, Graaf Y, Steensel CJ, Boelhouwer RU, Clevers GJ, Meijer WS, Stassen LPS, Vente JP, Weidema WF, Schrijvers AJP, Vroonhoven TJMV. Comparison of conventional anterior surgery and laparoscopic surgery for inguinal hernia repair. N Engl J Med 1997;336: 1541-7.

4. Read RC. Attenuation of the rectus sheath in inguinal herniation. Am J Surg. 1970;120:610-4.

5. Wagh PV, Read RC. Collagen deficiency in the rectus shealth of patients with inguinal herniation. Proc Soc Exp Biol Med 1971;137:382-4

6. Conner WT, Peacock EE. Some studies on the etiology of inguinal hernia. Am J Surg. 1973;126:732-5.

7. Cannon DJ, Read RC. Metastatic emphysema: a mechanism for acquiring inguinal herniation. Ann Surg 1981;194:270-8.

8. Baradi AF, Heslop JH, Rao NS. Peritoneal fine structure of inguinal hernia: a scanning electron microscope study. Histol Histopathol.1986;1:89-92.

9. Ajabnoor MA, Mokhtar AM, Rafee AA, Taha AM. Defective collagen metabolism in Saudi patients with hernia. Ann Clin Biochem 1992;29:430-6.

10. Wagh PV, Leverich AP, Sun CN, White HA, Read RC. Direct inguinal herniation in men: a disease of collagen. J Surg Res 1974, 17:425-33.

11. Friedman DW, Boyd CD, Norton P, Greco RS, Boyarsky AH, Mackenzie JW, Deak SB. Increases in type III collagen gene expression and protein synthesis in patients with inguinal hernias. Ann Surg 1993;218:754-60.

12. Bellón JM, Buján J, Honduvilla NG, Jurado F, Gimeno MJ, Turnay J, Olmo N, Lizarbe MA. Study of biochemical substrate and role of metalloproteinases in fascia transversalis from hernial processes. Eur J Clin Invest 1997;27:510-6.

13. Montes GS, Junqueira LCU. The use of the Picrosiriuspolarization method for the study of biopathology of collagen. Mem Isnt Osvaldo Cruz 1991;86(Suppl. III):1-11.

14. Peacock EEJ. Internal reconstruction of the pelvic floor for recurrent groin hernia. Ann Surg 1984;200(3):321-7.

15. Pickering JG, Boughner DR. Quantitative assessment of the age of fibrotic lesions using polarized light microscopy and digital image analysis. Am J Pathol 1991;138(5):1225-31. 
Wolwacz Jr I, Trindade MRM, Cerski CT. The collagen in transversalis fascia of direct inguinal hérnia patients treated by videolaparoscopy. Acta Cir Bras [serial online] 2003 May-Jun;18(3). Available from URL: http://www.scielo.br/acb.

ABSTRACT - Purpose: To analyse in respect to thickness, constitutive elements and total collagen quantification, samples of transversalis fascia from direct inguinal hernia patients, between twenty and sixty years of age and colected at the moment of laparoscopic repair, compairing with samples of the same tissue, obtained from corpse. Methods: We collected 23 samples from patients and 22 samples from corpse. The samples were stained for Hematoxiline-eosine and Sirius-Red. The video captured images were analysed by computer-assisted videomorphometric techenic. Results: We noticed the thickness of normal transversalis fascia to be 4.5 milimetres. Otherwise, the transversalis fascia from patients were $58 \%$ thinner $(\mathrm{p}<0.001)$. There was no evidence of any senile degenerative process involving the collagen fibres. The Dense connective tissue was the principal constitutive element in both groups being responsable for $75 \%$ of control's fascia and 49 $\%$ for the hernia one $(\mathrm{p}<0.001)$. The collagen's mean percentual area in the sample field from patients were half the control's area $(\mathrm{p}<0.001)$, stablishing that there are less collagen in the hernia's wall. Conclusion: The direct inguinal hernia patients have less collagen in transversalis fascia either absolutely or relatively to other constitutional elements.

KEY WORDS - Collagen. Hernia, inguinal. Transversalis fascia. Videolaparoscopy.

Conflito de interesse: nenhum

Fonte de financiamento: nenhuma

Correspondência:

Manoel Roberto Maciel Trindade

R. Hilário Ribeiro, 144/601

90510-040 Porto Alegre - RS

manoeltr@portoweb.com.br

Data do recebimento: 03/01/2003

Data da revisão: 19/01/2003

Data da aprovação: 27/01/2003 